Annales Geophysicae (2002) 20: 1899-1904 (c) European Geosciences Union 2002

\title{
SuperDARN E-region backscatter boundary in the dusk-midnight sector - tracer of equatorward boundary of the auroral oval
}

\author{
P. T. Jayachandran ${ }^{1}$, E. F. Donovan ${ }^{2}$, J. W. MacDougall ${ }^{1}$, D. R. Moorcroft ${ }^{1}$, J.-P. St. Maurice ${ }^{1}$, and P. Prikryl ${ }^{3}$ \\ ${ }^{1}$ Department of Physics and Astronomy, University of Western Ontario, London, Ontario, Canada \\ ${ }^{2}$ Institute for Space Research and Department of Physics, University of Calgary, Calgary, Alberta, Canada \\ ${ }^{3}$ Communications Research Centre, Ottawa, Ontario, Canada
}

Received: 12 April 2002 - Revised: 27 June 2002 - Accepted: 2 July 2002

\begin{abstract}
We compare the locations of the equatorward boundaries of SuperDARN E-region backscatter and $H_{\beta}$ emissions, focusing on the dusk-midnight sector of the auroral oval where the proton aurora is statistically located equatorward of the discrete electron aurora. We show that, whenever both boundaries can be simultaneously identified, they are coincident. Our result complements earlier studies, which demonstrated the correspondence between the DMSP b2 $\mathrm{i}$ boundary and both the equatorward boundary of the proton auroral oval (Donovan et al., 2002), and the equatorward boundary of SuperDARN E-region echoes (Jayachandran et al., 2002). Further, our result shows that, provided there is sufficient precipitating proton energy flux, the SuperDARN radars can be used to monitor the equatorward edge of the proton auroral oval.
\end{abstract}

Key words. Ionosphere (auroral ionosphere; particle precipitation; ionospheric irregularities)

\section{Introduction}

The development of techniques capable of continuous tracking of the location and dynamics of the auroral oval is an important objective in auroral and Solar Wind-MagnetosphereIonosphere (SW-M-I) coupling research. The auroral oval, which is comprised of precipitating electrons and protons, undergoes dynamic behavior in the dusk-midnight sector. Morphological studies based on satellite particle and groundbased optical measurements have shown that in the duskmidnight sector, the diffuse auroral ion precipitation is, on average, situated equatorward of the discrete auroral electron precipitation (Akasofu, 1974; Feldstein and Galperin, 1985; Gussenhoven et al., 1987; Hardy et al., 1989). The most equatorward boundary of the auroral oval is the location where high-energy ions stop precipitating (i.e. the transition between bounce trapping and strong pitch-angle scattering). The equatorward cutoff of ion precipitation corre-

Correspondence to: P. T. Jayachandran (jaya@uwo.ca) sponds to both the ion isotropy and b2i boundaries (Sergeev et al., 1983; Newell et al., 1996, 1998).

The optical manifestation of the high-energy ion (proton) precipitation is the presence of strong $H_{\beta}(486.1 \mathrm{~nm})$ emission (Eather, 1967a; Donovan et al., 2002). In the evening sector, the location of the $H_{\beta}$ boundary is a good groundbased indicator of the equatorward edge of the auroral oval when compared to oxygen emission at 557.7 and $630.0 \mathrm{~nm}$, because statistically the proton precipitation extends equatorward of the electron precipitation in the dusk-midnight sector, and the $H_{\beta}$ emission is an unambiguous indicator of ion precipitations. Moreover, 557.7 and $630.0 \mathrm{~nm}$ emissions can be contaminated by secondary processes associated with proton (ion) precipitation (Eather, 1967a; Rees, 1987).

To date, studies of the relationship between optical auroral forms and radio-wave backscatter (Herlofson, 1947; Bates et al., 1969; Greenwald et al., 1975; Romick et al., 1974; Moller, 1974; Hall et al., 1990; Prikryl et al., 1995; Milan et al., 2000) have been based on active auroral forms. They have shown reasonable temporal correlation between the optical aurora and radio-wave backscatter. Since the installation of the SuperDARN radars (Greenwald et al., 1995), which have a wide area of coverage, it has become possible to monitor the auroral ionosphere whenever decameter ionospheric irregularities are present. Recent studies by Jayachandran et al. $(2000,2001)$ have shown that the SLow ERegion Plasma Structures (SLERPS) type of SuperDARN Eregion backscatter in the dusk-midnight sector is from the region of ion (proton) precipitation. It has also been shown by Jayachandran et al. (2002) that the equatorward edge of the E-region backscatter, detected by the Saskatoon and Kapuskasing pair of SuperDARN radar, coincides with the equatorward boundary of ion precipitation, as indicated by the b2i boundary. Donovan et al. (2002) used DMSP ion energy spectra and ground-based $H_{\beta}$ observations to show that the equatorward boundary of the $H_{\beta}$ emission corresponds to the $\mathrm{b} 2 \mathrm{i}$ boundary. They developed a straightforward algorithm for identifying what they referred to as the "optical b2i boundary". In this study, we extend the work of Jayachan- 

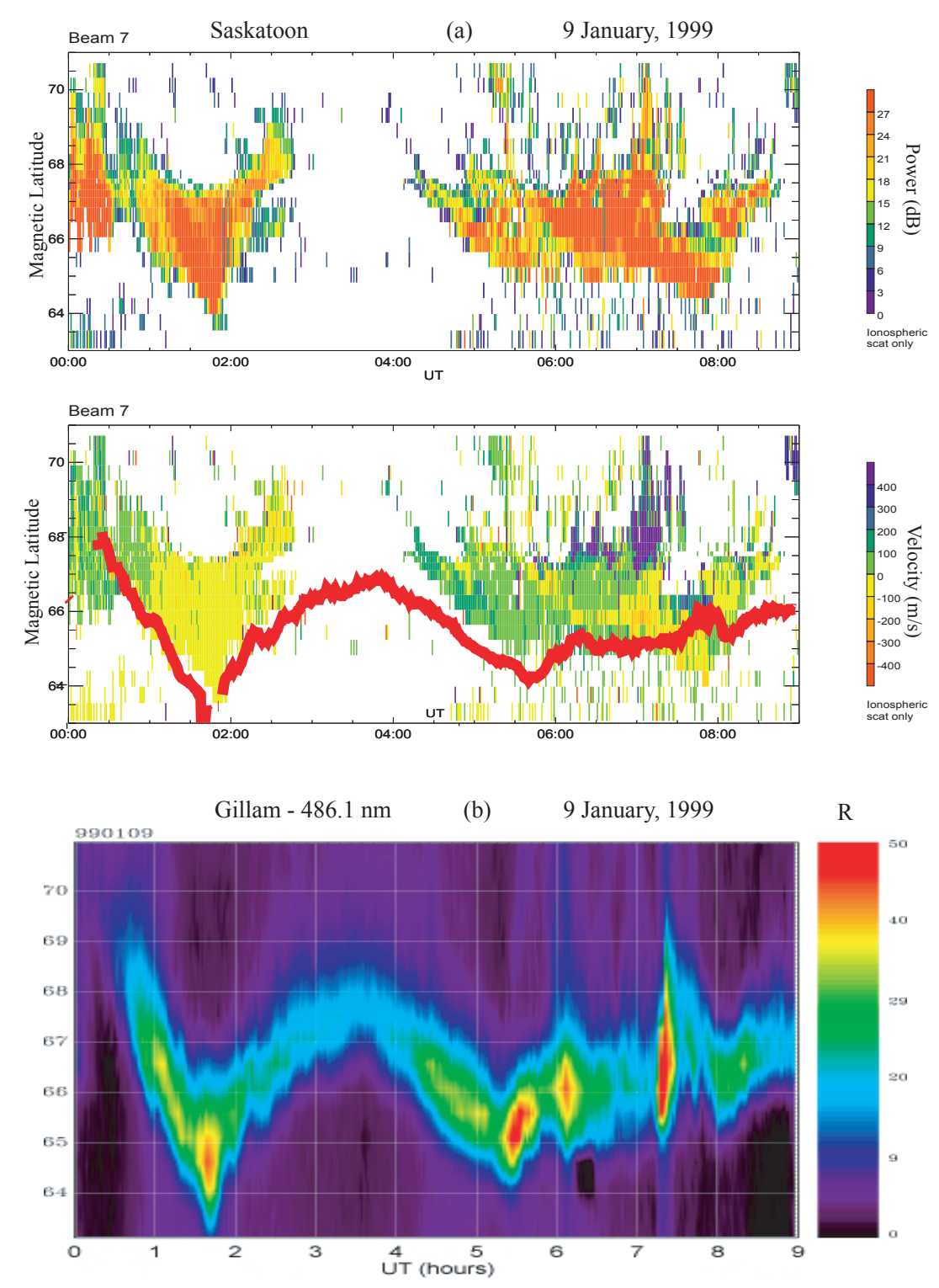

Fig. 1. (a) Latitude Time Intensity (LTI) plot (top panel) and Latitude Time Velocity (LTV) plot (bottom panel) of Saskatoon radar for beam 7 during 00:00-09:00 UT of 9 January 1999. (b) Keogram of 486.1 $\left(H_{\beta}\right)$ emissions obtained by Gillam MSP for the same duration as the radar data. The latitudes shown in the figure are magnetic latitudes (AACGM). The solid line in the middle panel represents the location of the equatorward boundary of $H_{\beta}$ emission determined using the method of Donovan et al. (2002).

dran et al. (2002) and Donovan et al. (2002) and demonstrate the correspondence between the equatorward edge of the Eregion backscatter and the optical b2i boundary. We also demonstrate the capability of SuperDARN radars to monitor the auroral oval boundary by using the E-region backscatter boundary as a tracer.

\section{Experimental details and results}

For this study we utilized data from the Saskatoon (CGM Lat. $61.31^{\circ} \mathrm{N}$, Long. $\left.316^{\circ} \mathrm{E}\right)$ SuperDARN radar and the Gillam (CGM. Lat. $67.47^{\circ}$ N, Long. $329^{\circ}$ E) Meridian Scanning Photometer (MSP), which is part of the Canadian Auro- ral Network for the OPEN Program Unified Study (CANOPUS).

SuperDARN radars are deployed to study the large-scale ionospheric F-region convection pattern in high latitudes. Presently, these radars cover much of the high-latitude regions of the Northern and Southern Hemispheres. A detailed description of the radar array and their characteristics can be found in Greenwald et al. (1995). The radars operate in the frequency range of $8-20 \mathrm{MHz}$ (HF). Their antenna system consists of a main array of $16 \log$ periodic antennas and an additional array of 4 antennas (the interferometer array, which is used for the angle of arrival measurements). Due to the physical design of the antenna array, the beam patterns 
Saskatoon - Beam 7

(a)

6 February, 1997

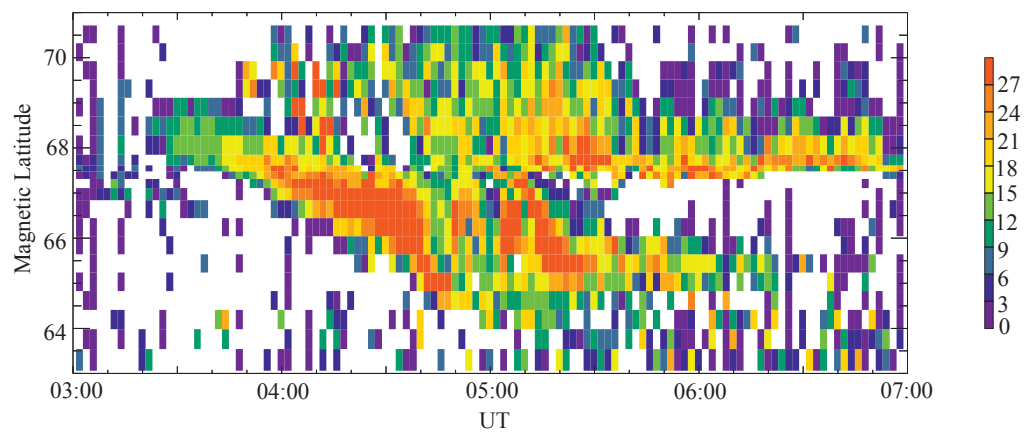

Ð
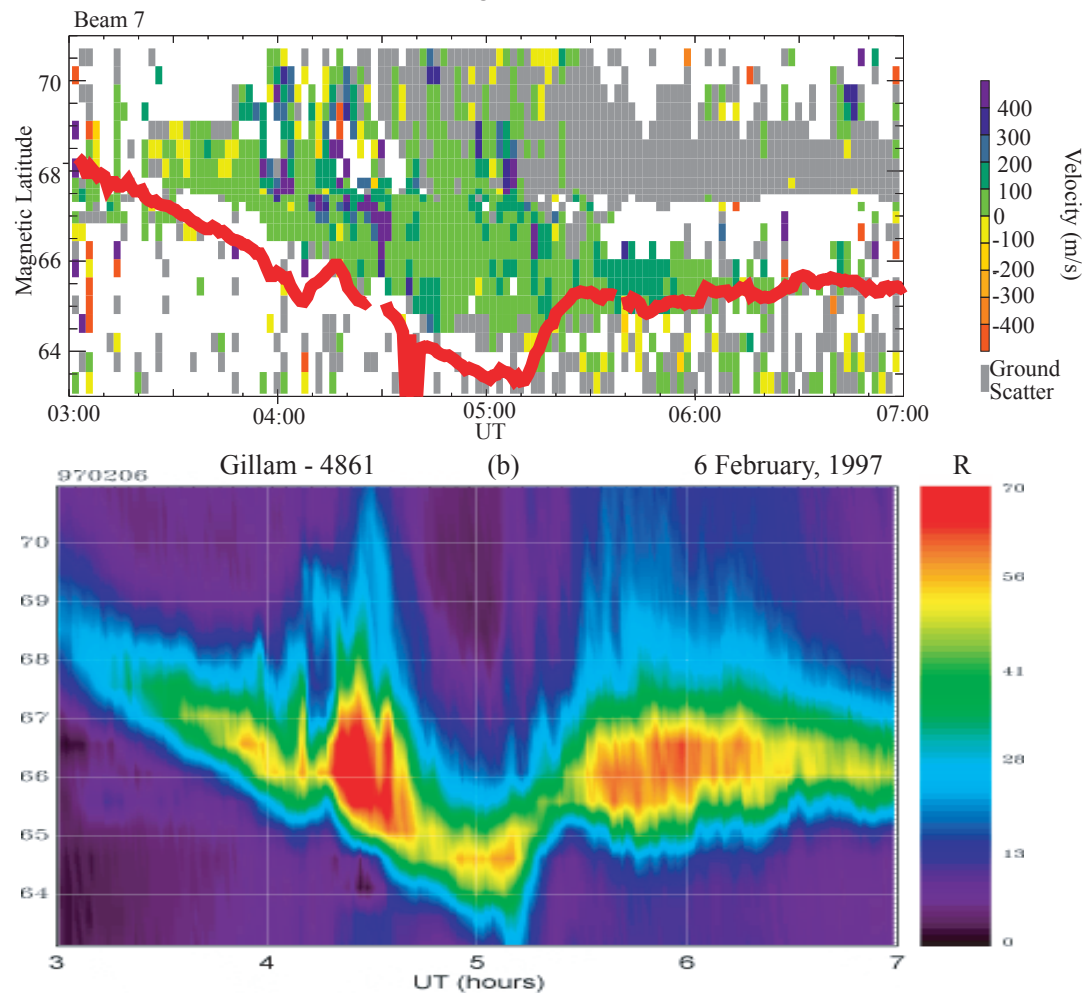

Fig. 2. Format and order is the same as Fig. 1 but for 6 February 1997.

are narrow $\left(2^{\circ}-4^{\circ}\right.$, depending on the frequency) in the horizontal direction and broad $\left(30^{\circ}\right)$ in the vertical direction. The antenna pattern consists of 16 azimuthally pointing directions (beams) separated by $\sim 2.3^{\circ}$. This configuration gives wide coverage of the high-latitude ionosphere.

The Gillam MSP provides meridional profiles of auroral intensities at a number of scientifically relevant wavelengths, including $486 \mathrm{~nm}$, which corresponds to the Hydrogen Balmer-beta electronic transition, and, in turn, unambiguously indicates proton auroral precipitation (Eather, 1976a). As stated above, Donovan et al. (2002) developed an algorithm to infer the location of the b2i boundary from Gillam $486 \mathrm{~nm}$ MSP data. In their method a Gaussian is fit to the $H_{\beta}$ emission profile, and the optical b2i is 1.4 standard deviations south of the maximum $H_{\beta}$ emission. This method was developed by intercomparing $H_{\beta}$ emission profiles and b2i boundary values determined directly from DMSP data, for 29 over flights of Gillam.

We have used the data from SuperDARN Saskatoon radar beam 7, which is approximately parallel to the Gillam MSP scan. A typical example of simultaneous radar and MSP $H_{\beta}$ data is shown in Fig. 1. The top two panels of the figure show the Latitude Time Intensity (LTI) and Latitude Time Velocity (LTV) plots for beam 7 between the hours 00:0009:00 UT of 9 January 1997. The bottom panel shows the corresponding Keogram of the $H_{\beta}$ emission for the Gillam MSP. The solid line in the middle panel represents the location of the equatorward boundary of the $H_{\beta}$ emission, determined using the method of Donovan et al. (2002). This example is chosen because it shows all the properties of the $H_{\beta}$ emissions, radio-wave backscatter, as well as the dynamics of the auroral oval in the dusk-midnight sector (MLT midnight is $\sim 07: 30$ UT). The latitudes shown are in AACGM (Baker and Wing, 1989), and the Gillam $H_{\beta}$ emission and the 


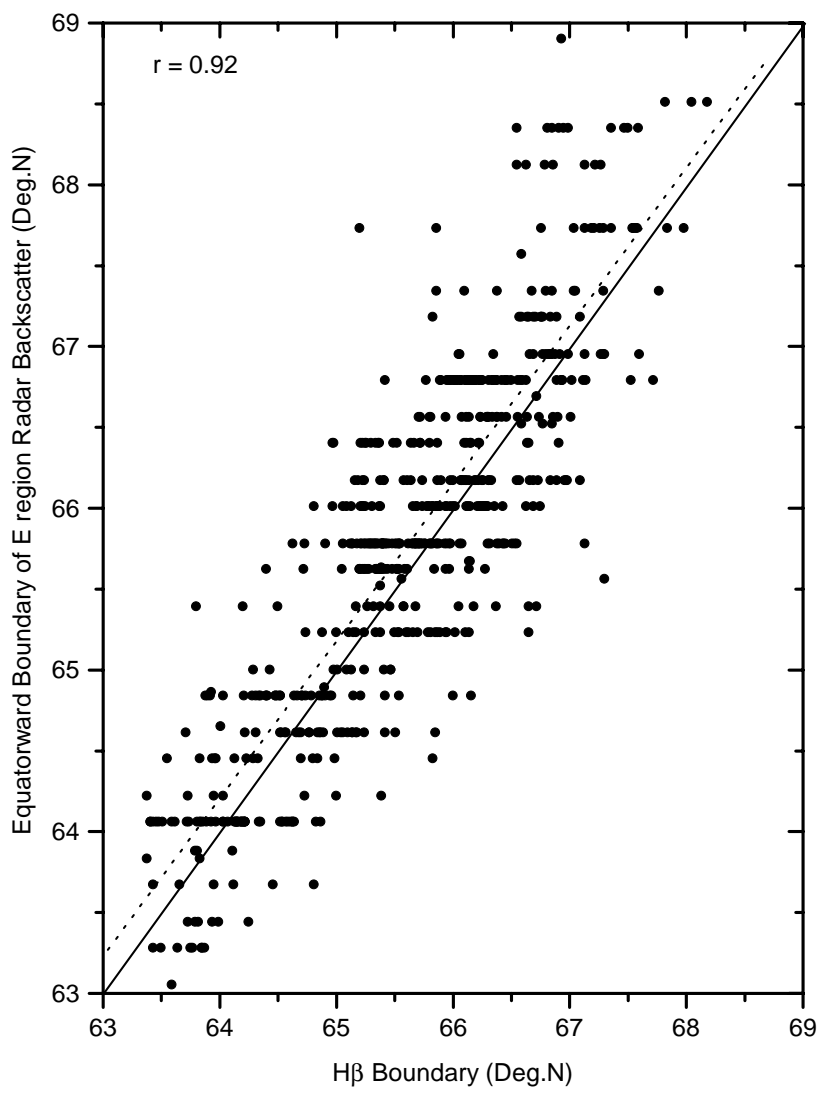

Fig. 3. Scatter plot showing the comparison of equatorward boundaries of $H_{\beta}$ emission and radar backscatter. Dashed line is a linear best fit to the data and the correlation coefficient is 0.92 .

backscatter is converted to AACGM, assuming the height of $110 \mathrm{~km}$. Since we are interested in the equatorward boundaries inferred from these two different observations, we will not be discussing other obvious interesting features in the data shown in Fig. 1. An examination of these two observations shows that the equatorward boundary of the radar backscatter coincides with the equatorward boundary of the $H_{\beta}$ emission, and both $H_{\beta}$ emission and radar backscatter regions exhibit similar dynamical behavior. Note that there was no backscatter between 02:40 UT and 04:10 UT, when the emission layer was moving poleward and the emission intensity was $<20 R$. Backscatter reappeared when the emission region moved equatorward and the intensity exceeded $20 R$. One other observational fact is that there is no SLERPS type E-region backscatter when the intensity of $H_{\beta}$ emission is less than $20 R$. This is not the only required condition of the observation of SLERPS. The electric field direction also plays a role in the formation of SLERPS. A detailed study is in progress regarding the $H_{\beta}$ intensity, electric field direction and the E-region backscatter.

Another example of simultaneous SuperDARN and MSP data for 6 February 1997 is shown in Fig. 2. The order and format of the figure are the same as in Fig. 1. Both the $H_{\beta}$ emission and the radar backscatter show very similar trends in latitude and the equatorward boundaries inferred from these two observations are approximately the same.

These two examples show a close association between the $H_{\beta}$ emission and SLERPS type E-region backscatter and nearly corresponding equatorward boundaries of these two different observations. By scanning the data from Gillam MSP and Saskatoon SuperDARN radar for the years 19961999 , we have identified the $102 \mathrm{~h}$ of simultaneous observations. The equatorward boundary of $H_{\beta}$ emission is identified by the method of Donovan et al. (2002), as discussed above. The equatorward E-region radar backscatter boundary was then identified using the following three-step process: (1) eliminate ground and meteor scatter echoes from the database using the method of Hall et al. (1997) and Andre et al. (1998), (2) check the data for the presence of ionospheric E-region scatter in three successive range bins and three successive scans to further avoid any spurious points, and (3) determine the latitude of the nearest (most southerly) range bin of the ionospheric E-region scatter. The latitudes used in this study are magnetic latitudes. The lowest latitude of detection of E-region backscatter is limited by the location of the radar (for Saskatoon it is $62.8^{\circ}$ ), and the maximum range for direct E-region backscatter limits the highest latitude. By using the angle of arrival information to identify the region of E-region backscatter, we have found that the maximum range is $990 \mathrm{~km}$ (range below which the backscatter is unambiguously from the E-region), so that the highest latitude is $\sim 70^{\circ}$.

Figure 3 is a scatter plot of the two boundaries for the $102 \mathrm{~h}$ of simultaneous observations. The solid line in the figure is the $45^{\circ}$ line, and the dashed line is the linear best fit to the data. The scatter in the plot may be due to the fact that there are differences in resolution of the two boundaries. The radar boundary resolution is $\sim 0.35^{\circ}$ whereas the $H_{\beta}$ boundary is determined from the Gaussian-fitted meridional intensity profiles. It is evident from the figure that the two boundaries agree very well (the correlation coefficient is 0.92 ).

\section{Discussions and conclusion}

The primary goal of this paper is to show that the equatorward boundary of the SLERPS type E-region backscatter can be used as a tracer of the equatorward edge of the energetic proton (ion) precipitation, as indicated by either the b2i or boundary or equatorward edge of the proton aurora (i.e. the optical b2i). The fact that all SLERPS type SuperDARN backscatter occurs in the dusk-midnight sector (Huber, 1999; Jayachandran et al., 2000), and that the protons (ion) precipitations are typically equatorward of the electron precipitation in the dusk-midnight sector also means that SLERPS are effectively a tracer of the equatorward boundary of the auroral oval. The obvious relationship between these two boundaries is clear from Fig. 1. Most of the previous studies (Greenwald et al., 1975, 1975; Romick et al., 1974; Hall et al., 1990; Milan et al., 2001) on the relationship between the optical auroral forms and radio-wave backscatter based on the active (discrete) visual auroral forms have suggested that there exists a 
relationship between the radio and optical aurora but they were not co-located. In general, they have suggested that radar backscatter is observed equatorward of the active optical aurora in the eastward electrojet region (dusk-midnight sector). Studies based on particle and optical measurements (Akasofu, 1974; Feldstein and Galperin, 1985; Hardy et al., 1989; Gussenhoven et al., 1987) have shown that, on average, there exists a region of diffuse aurora (ion precipitation) equatorward of the discrete aurora (electron precipitation) in the dusk-midnight sector. The good agreement between these two boundaries shown in Fig. 3 is understandable since we are comparing the radar backscatter boundary with the $H_{\beta}$ boundary, and the $H_{\beta}$ emission (diffuse aurora) generally lies equatorward of the discrete aurora in the dusk-midnight sector.

We are also in a position to comment on why SLERPS type E-region backscatter is associated with proton precipitation. Since we are dealing with SuperDARN, which operates at HF, vertical gradients of the ionization play an even more important role in the generation of irregularities than at VHF (St.-Maurice et al., 1994). The association of observed Eregion irregularities with proton aurora and high-energy ion precipitations suggests that these irregularities are formed through a gradient drift mechanism. The $H_{\beta}$ emissions are due primarily to several to tens of $\mathrm{KeV}$ precipitating CPS protons, which deposit most of their energy in the E-region (Vontrat-Reberac et al., 2001), and produce steep gradients in electron density. This gradient, and a properly directed electric field makes the E-region unstable through the gradient drift instability mechanism and produces irregularities and thus radiow-ave backscatter. Generally, in the dusk-midnight sector of the auroral oval, the electric field is directed northward, and the bottom side of the E-region is unstable through the gradient drift instability mechanism. Further, the absence of E-region backscatter if the $H_{\beta}$ intensity is $<20 R$ and the disappearance of the backscatter if the electric field changes its directions also confirms that the generation mechanism of these irregularities is gradient drift instability.

It should be emphasized that other factors, such as refraction and radar geometry (location), affect the detection of HF irregularities. This can have important consequences in the detection of SLERPS and identification of the boundary. This study and an earlier study (Jayachandran et al., 2002) shows the capability of Saskatoon, Kapuskasing and Goose Bay SuperDARN radar to identify the equatorward boundary of the auroral oval using the E-region backscatter. Uspensky et al. (2001) have also reported the presence of "ribbon echoes" (narrow region of E-region backscatter) from the diffuse auroral region using the SuperDARN Finland radar. The Finland radar geometry is different from the radar used in this study. For the Finland radar, the incident radar wave is almost perpendicular to the magnetic field (condition required for radio backscatter) without refraction, implying that refraction actually produces a negative effect (bends the ray away from perpendicularity). Hence, the irregularities are detected only from the region where there is no refraction (region where the ray is orthogonal to the isoelectron density surface). This is in contrast to the Saskatoon radar for which the incident rays are a few degrees from the normal, and refraction is necessary to obtain perpendicularity. A detailed study is required to determine which of the SuperDARN radars can actually determine the auroral boundary, taking all the factors into consideration.

The establishment of a close relationship between the equatorward boundaries of the auroral oval and the E-region backscatter is important since SuperDARN can provide another ground-based tool for continuous temporal and spatial monitoring of the dynamics of the auroral oval, which in turn can lead to the better understanding the physics and dynamics of the substorm growth and expansion phase.

Acknowledgements. This research was supported by grants from the Natural Science and Engineering Research Council (NSERC) of Canada. Operation of the Saskatoon SuperDARN radar is supported by NSERC of Canada. Operation of Gillam MSP, which is part of CANOPUS is supported by Canadian Space Agency and F. Creutzberg is the scientist responsible for the operation of the CANOPUS MSPs.

Topical Editor M. Lester thanks T. Yeoman for his help in evaluating this paper.

\section{References}

Akasofu, S-I.: Discrete, continuous and diffuse auroras, Plannet. Space. Sci., 22, 1723, 1974.

Andre, D., Sofko, G. J., Koustov, A. V., Baker, K., and MacDougall, J. W.: SuperDARN interferometry: Meteor echoes and electron densities from ground scatter, J. Geophys. Res., 103, 7003, 1998.

Baker, K. B. and Wing, S.: A new magnetic coordinates system for conjugate studies at high latitudes, J. Geophys. Res., 90, 6387, 1989.

Bates, H. F., Sharp, R. D., Belon, A. E., and Boyd, J. S.: Spatial relationship between HF radar aurora, optical aurora and electron precipitation, Planet. Space. Sci., 17, 83, 1969.

Donovan, E. F., Jackel, B. J., Voronkov, I., Sotirelis, T., Creutzberg, F., and Nicholson, N. A.: Ground-based optical determination of the b2i boundary: A basis for an optical MT-index, J. Geophys. Res., accepted, 2002.

Eather, R. H.: Secondary processes in proton aurora, J. Geophys. Res., 72, 1481, 1976a.

Eather, R. H.: Auroral proton precipitation and Hydrogen Emissions, Rev. Geophys., 5, 207, 1967b.

Feldstein, Y. I. and Galperin, Y. I.: The auroral luminosity structure in the High-Latitude Upper atmosphere: Its dynamics and relationship to the large-scale structure of the Earth's magnetosphere, Rev. of Geophys., 23, 217, 1985.

Greenwald, R. A., Ecklund, W. L., and Balsley, B. B.: Auroral currents, irregularities, and luminosity, J. Geophys. Res., 78, 8193, 1975.

Greenwald, R. A., Baker, K. B., Dudenay, J. R. et al.: DARN/ SuperDARN: A global view of high latitude convection, Space. Sci., Rev., 71, 763, 1995.

Gussenhoven, M. S., Hardy, D. A., and Heinemann, N.: The equatorward boundary of auroral ion precipitation, J. Geophys. Res., 94, 3273, 1987.

Hall, G. E., Moorcroft, D. R., Cogger, L. L., and Andre, D.: Spatial relationship between large aspect angle VHF radio aurora and 
$557.7 \mathrm{~nm}$ emissions: Evidence for refraction, J. Geophys. Res., 95, $15281,1990$.

Hall, G. E., MacDougall, J. W., Moorcroft, D. R., St-Maurice, J.-P., Manson, A. H., and Meek, C. E.: Super Dual auroral radar network observation of meteor echoes, J. Geophys. Res., 102, 14 603, 1997.

Hardy, D. A., Gussenhoven, M. S., and Brautigam, D.: A statistical model of auroral ion precipitation, J. Geophys. Res., 94, 370, 1989.

Herlofson, N.: Interpretation of radio echoes from polar aurora, Nature, 160, 867, 1947.

Huber, M.: HF radar echo statistics and spectral studies using SuperDARN, M.Sc. Thesis, University of Saskatoon, 1999.

Jayachandran, P. T., St.-Maurice, J.-P., MacDougall, J. W., and Moorcroft, D. R.: HF detection of slow long-lived E-region plasma structures, J. Geophys. Res., 105, 2425, 2000.

Jayachandran, P. T., MacDougall, J. W., St-Maurice, J.-P., Moorcroft, D. R., Prikryl, P., Newell, P. T., and Creutzberg, F.: Dynamics of the substorm growth phase-Multi instrument observations, Ann. Geophysicae, submitted, 2001.

Jayachandran, P. T., MacDougall, J. W., St-Maurice, J.-P., Moorcroft, D. R., Newell, P. T., and Prikryl, P.: Coincidence of the ion precipitation boundary with the HF E-region backscatter boundary in the dusk-midnight sector, Geophys. Res. Lett., 10.1029/2001GL014184, 2002.

Milan, S. E., Lester, M., Sato, N., Takizawa, H., and Villain, J.-P.: Investigation of the relationship between optical auroral forms and HF radar E-region backscatter, Ann. Geophysicae, 18, 608, 2000.

Milan, S. E., Lester, M., Sato, N., and Takizawa, H.: On the altitude dependence of the spectral characteristics of decameterwavelength E-region backscatter and the relationship with optical auroral forms, Ann. Geophysicae, 19, 205, 2001.

Moller, H. G.: Backscatter results from Lindau, II, The movements of curtains of intense irregularities in the polar F layer, J. Atmos.
Terr. Phys., 36, 1487, 1974.

Newell, P. T., Feldstein, Y. I., Galperin, Y. I., and Meng, C.-I.: Morphology of nightiside precipitation, J. Geophys. Res., 101, 10737, 1996.

Newell, P. T., Sergeev, V. A., Bikkuzina, G. R., and Wing, S.: Characterizing the state of the magnetosphere: Testing the ion isotropy boundary maxima latitude (b2i) and the ion isotropy boundary, J. Geophys. Res., 103, 4739, 1998.

Prikryl P. and Cogger, L. L.: Statistical analysis of the spatial relationship between radio and optical aurora: further evidence for refraction, Radio Sci., 27, 469-479, 1992.

Rees, M. H.: Physics and chemistry of the upper atmosphere, Cambridge University Press, 1987.

Romick, G. J., Ecklund, W. L., Greenwald, R. A., Balsley, B. B., and Imhof, W. L.: The relationship between the $>130 \mathrm{KeV}$ electron trapping boundary, the VHF radar backscatter, and the visual aurora, J. Geophys. Res., 79, 2439, 1974.

Sergeev, V. A., Sashina, E. M., Tsyganenko, N. A., Lundblad, J. A., and Soraas, F.: Pitch angle scattering of energetic protons in the magnetotail current sheet as the dominant source of their isotropic precipitation into the nightside ionosphere, Planet. Space Sci., 31, 1147, 1983.

St-Maurice, J.-P., Prikryl, P., Danskin, D. W., Hamza, A. M., Sofko, G. J., Koehler, J. A., Koustov, A. V., and Chen, J.: On the origin of narrow non-ion-acoustic coherent radar spectra in the highlatitude E-region, J. Geophys. Res., 99, 6467, 1994.

Vontrat-Reberac, R., Fontaine, D. R., Blelly, P. L., and Galand, M.: Theoretical predictions of the effect of cusp and dayside precipitation on the polar ionosphere, J. Geophys. Res., 106, 28857 , 2001.

Uspensky, M., Eglitis, P., Opgenoorth, H., Starkov, G., Pulkkinen, T., and Pellinen, R.: On auroral dynamics observed by HF radar: 1. Equatorward edge of the afternoon-evening diffuse luminosity belt, Ann. Geophysicae, 18, 1560, 2001. 